\title{
LA NARRATIVA DE GRISELDA GAMBARO: DIOS NO NOS QUIERE CONTENTOS
}

POR

\author{
HORTENSIA R. MORELL \\ Temple University
}

No obstante la extensa obra narrativa de la escritora argentina Griselda Gambaro, obra que los editores de su teatro califican de "contundente" (Giella et al, 5), premiada en su país y traducida a varios idiomas, la gran mayoría de la crítica dedicada a la autora se concentra en su producción dramática ${ }^{1}$. Se le reconoce la importancia de su teatroinnovador, escenario que, en su problemática de la violencia y del poder, es imagen de la crisis individual y colectiva de la nación, pero en general se desatienden sus cuentos y novelas. Es precisamente la novela Ganarse la muerte (1977), alusiva, en el personaje de Cledy, a la Argentina víctima de la tortura institucionalizada, la obra que recibe la censura oficial y ocasiona el exilio de Gambaro en España y Francia de 1977 a 1980 (Betsko y Koening, 184)2. Este vacío crítico resulta más insólito cuando se observa que la escritora se inicia, de hecho, en la narrativa con Madrigal en ciudad (1963), y que sus primeras piezas importantes (Las paredes, El desatino, El campo), así como la pieza que marca la señal de un cambio en su producción

\footnotetext{
${ }^{1}$ Griselda Gambaro ha publicado la siguiente obra narrativa Madrigal en ciudad (1963), obra premida que incluye tres novelas cortas, "La infancia feliz de Petra", "El nacimiento postergado", y "Madrigal en ciudad"; $E l$ desatino (1965), obra premiada que incluye las novelas cortas "Las paredes" y "El desatino", y los cuentos "Los hombres", "Un final para Adán y Eva", "Relato donde toda la gente muere" y "Sumision"; Una felicidad con menos pena (1968), novela, mención especial; Nada que ver con otra historia (1972), novela; Ganarse la muerte (1976), novela traducida al francés; Dios no nos quiere contentos (1979), novela traducida al polaco; Lo impenetrable (1984), novela; La cola mágica (1976), cuento para niños. Sin embargo, sólo tengo constancia de dos críticos que comentan esta parte de su obra, Picon Garfield y Karvelis.

${ }^{2}$ Gambaro aclara: "I wrote the banned novel Ganarse la muerte [To Earn One's Death]. The main character was a woman. I didn't think she reflected the state of women; I thought she reflected Argentina. But the novel was published in French by the Women's Press [Ganer sa mort, Editions des Femmes, 1976] and they invited me to France. I had the opportunity to meet the feminists of France, and I began reading about the specific problems related to women. I started to realize things which, before that time, I had only felt in an instinctive way" (Betsko y Koening, 194-95).
} 
dramática (Nada que ver), aparecen todas primero en forma narrativa (Giella et al, 21-22). Además, su cuento infantil ilustrado La cola mágica (1975), se publica en una colección de tomos que incluye, entre otros autores de reconocido calibre narrativo, a Michel Butor, Augusto Roa Bastos, Silvina Ocampo y Clarice Lispector.

Gambaro defiende la narrativa y el teatro en tanto "alternativas de trabajo", opciones legítimas de acercarse al público (Giella et al, 22), Si valora la calidad colectiva del fenómeno teatral en "un público presente que termine el espectáculo" (Gambaro, 1987, 26), también anota en la novela una calidad particularmente reflexiva e introspectiva ${ }^{3}$. Con relación a Dios no nos quiere contentos (1979), novela escrita en su exilio barcelonés, comenta cómo deja reflexionar allí a su propia voz de autora, buscando respuestas que no son sólo para sus personajes, sino para ella misma en ese período confuso ${ }^{4}$. En esa búsqueda personal, recrea un Buenos Aires desgraciado por los desastres de El Proceso(1976-1983), la Guerra Sucia, el Buenos Aires de las Villas Emergencia, Villas Miseria que desaparecen tan fácilmente como sus habitantes ${ }^{5}$. Es la ciudad donde un autobús equivocado puede llevar a la Quiaca o a los abusos de un pederasta, y otro, atestado, a la desaparición de un bebé separado de su madre. Es el escenario de la "tragedia del poder y la fuerza" (137) donde ese mismo bebé intuye los terrores de la comisaria y sus "imágenes de espanto" (73), y se defiende de los peligros de la calle, uniformados "armados hasta los dientes", y "los otros uniformados, los que se mimetizaban de hippies y sediciosos... . Ya no perseguían planes revolucionarios sino exceso de sentimientos, sombras de inteligencia" (138). Allí un sueño frustrado conduce a la realidad de un lupanar pesadillesco, mientras que el infierno de los circos de mala muerte posiblilita el único cielo en el trapecio de la protagonista, la Ecuyere (Rosa).

Para una escritora que pocas veces especifica los espacios en su obra, es un Buenos Aires extrañamente nombrado, familiar, como la voz narradora omnisciente que entreteje dichos, refranes y meditaciones sobre la existencia

\footnotetext{
${ }^{3}$ Explica la autora: "lately, I find a need to create novels. They allow for a type of introspection, or reflection, which differs from dramatic action" (Picon Garfield, 60).

${ }^{4}$ Añade Gambaro, "Furthermore, in Dios no nos quiere contentos ... there is a search for an answer in which I, the author, am implicated; I allow myself to reflect with my own voice among my characters" (Picon Garfield, 71), y "El problema es que yo misma tengo que darme una buena respuesta. En este momento, que es un momento muy asfixiante, yo misma necesito tener una respuesta buena, que no significa una respuesta positiva en un sentido convencional. Significa una respuesta para que el hombre permanezca entero en su interior, para que el hombre no se destruya, para que el hombre siga vivo. Son todas las respuestas que me doy a mí misma, porque tal vez por razones personales y sociales, se está muy desgarrado" (Giella et al, 17).

5 Esa especial vulnerabilidad de los marginados sociales bajo El Proceso es objeto de comentario de Simpson y Bennet (197-99).
} 
humana con las aventuras de sus personajes, mientras construye el equivalente para la novela del "cuento filosófico" de Voltaire". En este espacio se marca el camino azaroso y el desplazamiento de la Ecuyere (Rosa), que no es "ecuyere", sino contorsionista y finalmente trapecista, en busca de sus circos escurridizos. La sigue Tristán, huérfano de padres y de tierra: "La memoria le traía un país áspero y duro. La madre que decapitaba a sus hijos ... la magnitud del paisaje se traducía en inmensidad de crueldades no gastadas, en infinidad de muertes" (59). Dentro de su miseria, Tristán se observa genuinamente movido por el arte de la Ecuyere, aunque enamorado de María, la niña que frente a la imposibilidad de salir milagrosamente de la pobreza, se decide por el prostíbulo. A la Ecuyere y Tristán se les une accidentalmente el bebé, figura de extraña madurez y sabiduría, que los salva en los momentos más difíciles.

En la construcción de la novela, que Gambaro reconoce compleja, la escritora utiliza una estructura de progresión cronológica y un desarrollo caracterológico que desafía las clasificaciones fáciles ${ }^{7}$. Aunque la cronología se ofrece lineal, resulta muy difícil determinar exactamente la cantidad de tiempo transcurrido, el suficiente para que el bebé crezca y se convierta en padre de otro bebé, y para que Maria y Tristán entren a la vida adulta. Registra la evolución de la Ecuyere desde su llegada a Buenos Aires, a casa de su hermano (el padre de María), a través de una serie de circos progresivamente decadentes, hasta su decisión de "decir no" al último. El desarrollo va de un momento inicial de egoísmo y vanidad profesionales a otro de auténtica revalorización del trabajo y la desgracia, de altruismo acrisolado por el sufrimiento de la desaparición y la muerte de los seres objetos de su amor (el rotoso) o amistad (José y Pepé, la amiga mansa), fuera y dentro del circo. Simultáneamente, lleva cuenta de la búsqueda de Tristán, mudo (y por eso contrafigura del Tristán mítico experto en lenguas y música), que persigue el amor de María y aprende a cantar, meta esta última que se constituye en motivo reiterativo, unificador de la novela ${ }^{8}$. Recoge

- Gambaro también hace referencias directas a Buenos Aires en la novela corta "El nacimiento postergado" y la "Crónica en veinte escenas" Informacion para extranjeros (1973). En su construcción del discurso de Dios no nos quiere contentos, la escritora se muestra en completo dominio de las técnicas narrativas de intercalación de discursos directos, indirectos e indirectos libres, y de un narrador cuya omniscencia casi editorial recuerda vagamente a Fielding. Más adelante desarrollo las conexiones ante Gambaro y Voltaire.

${ }_{7}^{7}$ Agrega Gambaro: "Technically, the novel's structure is more complex than that of my earlier works" (Picon Garfield, 71); "Las novelas que escribo ahora son de estructura más compleja ... ahora hay más introspección, más retroaccion" (Giella et al, 25). Dios no nos quiere contentos no es novela de formación, ni psicológica, ni de aventuras, aunque ofrece rasgos que la acercan a todas estas formas. Su fuerte carga lírico-reflexiva en combinación con esas corrientes la acercan más a lo que podría llamarse "novela filos6fica", en la vena del Candide de Voltaire. Más adelante exploro esa dirección.

B "Tristán, qué genio le había puesto ese nombre, felizmente aplanado, en la ignorancia de la gente, de su estatura dramática" (15). Para los avatares de esta figura mítica, véase de Rougement. Weston comenta que el Tristán de Wagner es notable por su capacidad de 
sus avatares desde el momento en que se convierte en huérfano por segunda vez cuando pierde a sus padres adoptivos en un terremoto, y se refugia en casa de María poco antes de la llegada de la Ecuyere, con la que decide partir, acompañados los dos del bebé. Tras de varias separaciones durante las cuales sufre la violación de su amor por María (obligado a tener relaciones sexuales con ella en el prostíbulo) (170-75), y muy luego, la de su imagen de niña al reencontrarla deteriorada e irreconocible en el Almacén La María (222-25), finalmente recibe el consuelo de la Ecuyere, cuando se reencuentran en la casa de prostitución clausurada. Posiblemente idiota, incapaz intelectualmente de enfrentar las dificultades en su camino, responde a los acontecimientos con un visceral "tengo que aprender a cantar".

Gambaro construye ese reencuentro, hace coincidir los dos hilos narrativos principales de las historias de la Ecuyere y Tristán, en el principio ambiguo, a la vez final de la novela. Reunidos en esa casa prostibularia abandonada, superan las miserias del suelo ascendiendo ambos al techo, como a otro cielo o trapecio, y cada uno emitiendo, milagrosamente, su canto. Mas la Ecuyere es la única capaz de oír a Tristán, quien duda de haber conseguido lo que antes tantas veces lo había frustrado: "Había aprendido a cantar. Se lo aseguró la Ecuyere cuando, al cabo de los años, lo encontró en la casa vieja que había sido un prostíbulo .... Lo había escuchado, inclinando la cabeza para que el canto de Tristán le cayera mejor en el oído, pero Tristán nole creyó"(7). La novela provoca la conjetura sobre si su testimonio no es sino la prueba de su crecimiento personal: "quizás el transcurrir del tiempo, con su carga de sabiduría, le había enseñado la generosidad con los otros"(7). Esa duda permite configurar la

cantar más dulcemente que ningún hombre ("more sweetly than any man"), y por sus habilidades en música y lenguas (Weston, 278, 282). Son características que ya se advertían en la fuente principal de Wagner, el Tristán de Gottfried von Strassburg. El Tristán de Gambaro difiere de otros porque siempre se conserva puro. Gambaro se acerca más a Wagner al utilizar a Tristán como motivo reiterativo a la manera del leitmotif wagneriano en su intento de aprender a cantar. La meta resulta ridícula, o increiblemente ambiciosa, para un niño mudo.

• "Hablaban de él, no con demasiada consideración, porque las palabras más frecuentes eran marmota, retardado e imbécil" (12); "-iSos idiota?- -... Tenía por fin una palabra que no era un regalo, de la que podría apropiarse y cobijar sin injusticia. Todo está en orden, pens 6 " (36). Tristán se hace el propósito de cantar durante el terremoto (10), y lo intenta en el entierro de sus padres adoptivos, cuando las consecuencias son desastrosas, "Para interrumpir sus mugidos, le pegaron discretamente, pero con fuerza" (18). Se reafirma en su propósito o en el intento fallido a través de toda la novela: en casa del pederastra del ómnibus (30); luego de la prueba cómicamente fallida de la Ecuyere como ecuestre (48); cuando la Ecuyere entra en su honda melancolía por el amor del rotoso (102); durante el episodio de la limpieza de la jaula del león del circo (116); cuando le regalan el disco de Gardel a la Ecuyere (150); cuando empieza la lenta recuperación de la Ecuyere $(156,157)$; durante la audición de la Ecuyere en el circo de verano (188); en la visita al bebé en su lecho de muerte (207, 211); en su visita al Almacén La María (223). 
estructura de la novela como hiato entre dos momentos del final. Motiva el recuento de los avatares de esa meta de Tristán de aprender a cantar desde sus inicios en el terremoto, la "circunstancia fortuita que le descubrió su vocación y destino", "la catástrofe que construyó dentro de él otra morada ... tengo que aprender a cantar" (8), hasta ese final reencuentro accidental: "-Bueno, ¿aprendiste?- Y Tristán negó. -Sí, aprendiste- dijo la Ecuyere. Ella escuchaba. Pero el canto de Tristán le daba pena" (252). Subidos los dos al techo de la casa con el apoyo de ella, parece no quedar lugar a dudas, "la Ecuyere comenzó a cantar como cuando estaba arriba, en el trapecio .... Ladeó la cabeza e interrumpió el canto para llamar a Tristán, con la precaución de quien despierta a un dormido, hasta que Tristán comprendió y largó su canto" (253). La novela se lee así de canto a canto, o entre canto dudado y canto confirmado, como un paréntesis que se cierra con el milagro del prostíbulo abandonado. Anticipando y recordando al mismo tiempo, la voz narradora se permite una serie de reflexiones sobre la naturaleza y la existencia humanas que hacen factible la transformación de la Ecuyere ${ }^{10}$.

Dios no nos quiere contentos se divide en veintidós secciones (a su vez subdivididas) sin marcar numéricamente. En la novela se alternan la vigilia y los sueños, clasificables, respectivamente, de acuerdo a la incapacidad oel poder hablar de Tristán ${ }^{11}$. Permanece mudo a través de las peripecias amorosas y profesionales de la Ecuyere, de los esfuerzos del bebé por sobrevivir ante los peligros de la calle (los de la represión) y de sus propias tentativas de reencontrar a María. En sus sueños, casi siempre pesadillas de reencuentro y desencuentro

10 “Obraba por vanidad, pero la vanidad era cáscara. Cáscara que se iría aligerando con el tiempo, la verdad estaba en la correspondencia, en eso que se producía entre Tristán y la Ecuyere" (46); "la inminencia del volver a trabajar la transformaba en una criatura complaciente y sumisa" (65); "estaba lejos de pensar que llegaría el día en que perdería todo" (74); "Esto es lo bueno de la carne, que el espíritu siempre la vence, cuando queda espíritu para vencerla" (116); "esa prisión privada e intransferible que es el amor. En esa prisión la Ecuyere estaba doblemente sola" (136); "la gente sale de sus pozos profundos de la mano del tiempo o de la muerte" (152); "La vocacion del ser humano es la felicidad, pero su ignorancia o su conciencia sobre la ignorancia de los otros, lo impulsan a la desdicha" (156); "La muerte final no importa, sino estas pequeñas muertes que nos paralizan en medio de la existencia. La resurección es siempre solitaria" (161); "el tiempo, por su sabiduría que nos dice que la vida es una sucesión de abandonos y encuentros, y que la vejez o menos vida es simplemente eso: menos posibilidades de despedidas y reencuentros" (237).

${ }_{11}$ Tristán habla en su primer sueño de visita a la casa de prostitución con Maria, donde la modalización del discurso y las proporciones cambiantes indican la calidad de pesadilla: "gigantescos", "como había visto en viejas películas de horror", "extrañamente", "misteriosamente" (41). Luego se repite su hablar en la pesadilla de visita al hotel con María (54-60), en el sueño del diluvio (78-83), en el segundo sueño de visita al prostíbulo con María (103-09), en el cortísimo sueño luego de la visita real al prostíbulo (175-76), y en el más complicado de todos, con una María tan cambiante como la Alicia onírica de Lewis Carroll (226-36). 
con María, Tristán habla sin problemas. Además, se intercalan las desgarradoras reflexiones de la Ecuyere, especialmente en cuatro subdivisiones que se señalan "Charlas que no se hicieron", seudo-diálogos apelativos a un Tristán ausente o incapaz de comprenderla, en los que le comunica su transformación por la experiencia y el dolor. Son pensamientos en la vena del Voltaire de Candide ou l'optimisme, cuando confirman la fe en el trabajo como respuesta a un mundo dolorosamente enajenado: "Cuando estoy allí arriba [en el trapecio] ... sé que todo está bien, aunque nunca entenderé las razones o sinrazones de la desgracia. No tengo otra respuesta .... Por eso me digo: todo está bien. Llorá Tristán, todo está bien" (221). Y en la última, que quiere sugerir la explicación del título de la novela, "Estamos hechos para vivir sin reconocer, Tristán. Para errar en un mundo que siempre nos cambia la verdad por mentira. Dios odia la alegría porque está hecho a nuestra imagen y semejanza, y no nos quiere contentos" (250). Esa reflexión completa otra de la Ecuyere donde se advierte mejor su fe, noobstante la arbitrariedad de sus pérdidas: "Qué lástima ese estrangulamiento continuo, ese encuentro que terminaba en la muerte y lo devoraba todo: sonrisas de niñez y amores .... Ya no entendía a los seres humanos, y como no podía soportarlo, porque los quería, pensó: Dios no nos quiere contentos" (249-50).

Mas Griselda Gambaro reconoce además en esta novela un cambio de dirección al crear en sus personajes y su mundo, antes casi siempre victimarios y víctimas monstruosas en su pasividad: ahora le parece que los desarrolla con ternura y comprensión, que los hace queribles, y que se acerca a ellos en un tono totalmente optimista ${ }^{12}$. En este sentido, la novela parece compendio de su obra, reunión de personajes antiguos y situaciones ya visitadas desde una perspectiva más humanizante, anuncio de su próxima transformación paralela en el teatro. Es como si, tal otro Tristán, muda por la censura, necesitara reafirmar lo creado a la vez que marcar una nueva ruta ${ }^{13}$. Su capacidad para captar la psicología de los niños (el bebé, María y Tristán) recuerda la del relato temprano "La infancia feliz de Petra", de Madrigal en ciudad (1963), sin su pesimismo, acercándose más a la de sus entrevistas Conversaciones con chicos (1976). La pérdida de control por amontonamiento humano en el ómnibus donde el bebé pierde a su mamá parece repetir la situación básica de la novela Una felicidad

\footnotetext{
${ }^{12}$ Gambaro entiende, "I believe the conclusion is optimistic, though my husband says it's very sad", "in that book [Dios no nos quiere contentos] I develop my characters in a new way, with a more tender, comprehensive attitude" (Picon Garfield, 69, 71), "Pienso que mi obra tiene actualmente elementos de ternura. Como me dice una amiga respecto a mi última novela [Dios no nos quiere contentos], es casi mozartiana. Es como si tuviera más comprensión por ciertas cosas, más ternura por lo que es la criatura humana. Por ejemplo, en esta última novela mis personajes que en general no son muy queribles, en ésta sí lo son" (Giella et al, 16).

${ }^{13}$ Hablando de la censura y la autocensura, Gambaro apunta "El camino yo lo tengo que buscar para no quedarme muda, ¿no?" (Giella et al, 9).
} 
con menos pena (1968). Sin embargo, el énfasis en la soledad y el egoísmo humanos de la obra temprana se sustituyen por la solaridad y la compasión de la segunda. La amiga mansa del circo, así como los trapecistas gemelos José y Pepé, evocan, respectivamente, una versión más humanizada de la Emma de $E l$ campo (1967) y de los protagonistas de Los siameses (1967). Esos trapecistas ancianos, así como el anciano del ómnibus del bebé, encerrados todos en un pasado nostálgico que dificulta la comunicación con el presente, parecen salir de los bancos de la plaza que visita Toni en Nada que ver con otra historia (1972). La amistad y el cuidado desinteresados de la Ecuyere logran, en el caso de José y Pepé, la reubicación en el presente y en el amor fraternal. Y el mismo Toni, redimido y madurado en el sufrimiento por la desaparición de Brigita María, parece renacer en la Ecuyere ante la desaparición del rotoso y las muertes de sus amigos del circo. Mas si Toni pierde la voluntad de vivir ante esa carga de sufrimientos, la Ecuyere, en cambio, se reafirma más y más en su lucha vital a través del dolor ${ }^{14}$.

Aunque ese optimismo gambariano resulte contradictorio dentro del panorama total de su desolador mundo creativo, y especialmente en una novela titulada Dios no nos quiere contentos, aunque resulte debatible dentro de la atmósfera sumamente densa de la novela, es factible observar cómo la escritora alcanza ese nivel tonal. Gambaro introduce la nota humorística en los momentos más trágicos, explorando el acervo de la corriente del grotesco criollo de Armando Discépolo, depurador de lo cómico sainetero, y que el escritor define como "el arte de llegar a lo cómico a través de lo dramático" (Ordaz 411) ${ }^{15}$. Desde el primer acontecimiento de la novela, el terremoto, se observa la vena tonal que marcará todo el suceder: "El [Tristán] pensó en seguida en su familia, allí dentro, pero siguió comiendo, porque temía otra vez pasar por maleducado o hacerles pasar vegüenza a sus padres adoptivos, porque si estaban en tren de ser sepultados adecuadamente por la mamposteria, y él se metía, no, no" (9).

El grotesco es la vena teatral donde Gambaro siempre se ha querido ver instalada, negando su entronque con el absurdo europeo ${ }^{16}$. Y aquí enlaza esa

\footnotetext{
${ }^{14}$ Explica la escritora sobre Nada que ver con otra historia, "la novela terminaba con un suicidio, o se insinuaba un suicidio, en cambio en la versión teatral el final es otro.... Por exigencias de la visión teatral. Un suicidio no me agradaba para la escena, no podía justificar ese final" (Giella et al, 34).

${ }^{15}$ Ordaz cita también del "Prologo" de David Viñas a las Obras escogidas de Armando Discépolo (Buenos Aires: Jorge Alvarez, 1969), "El grotesco aparece como la interiorización del sainete ... es la forma superior del contenido de una forma inferior que, en este caso, representa el sainete" (Ordaz, 88).

${ }_{16}$ Reconoce Gambaro, “A mí, particularmente, el sainete y el grotesco es lo que más me interesa, y cuando escucho que hacen análisis de mis obras y como parámetro usan el teatro del absurdo, siento una especie de retorcimento ... la mezcla de lo poético, lo trágico y lo tragicómico que hay en muchas de mis piezas. Eso no sale del teatro del absurdo, eso sale del grotesco" (Giella et al, 13), y "We come from Argentinian dramaturgy, a gender called grotesco [grotesque] created by a playwright named Armando Discépolo [1887. 1971]. We don't come from European absurdism" (Betsko y Koening, 195).
} 
corriente con la muy cercana del compositor de tangos Enrique, hermano de Armando y escritor también de piezas dramáticas (Ordaz 422) ${ }^{17}$. En el jocoso y a un tiempo trágico episodio del robo de los rotosos, por ejemplo, para connotar los vaivenes de la suerte, "Generalmente, el bienestar y la alegria de unos es tristeza para otros, por rebote" (86), el tema clásico de la rueda de la fortuna, introduce el motivo de la eterna sonrisa de la foto de Gardel atesorada por la Ecuyere. El rotoso toma, emocionado, la sonriente foto como parte de su botín, "deslumbrado por la blanca y gran sonrisa, y dijo: -iMacho! ¡Macho lindo y peludo!- y se guardó la fotografía en el bolsillo, que estaba roto, y de donde asomaba, por el rasgón del medio, la sonrisa del Cantor, cumpliendo con su destino de astro más allá de la muerte" (87). Mas termina, gracias a la astucia incendiaria del bebé, perdiendo todo lo robado más su carro y su caballo, quedando sus potenciales víctimas también despojadas, mas en posesión de su única rueda salvada: "Pudieron apartar una rueda del carro, que llevaron como adorno, apenas tostada" (89). Acentuando la precariedad de la fortuna, la Ecuyere, triunfante en ese episodio, al punto de despojar al rotoso de su rueda y hasta de un pedazo de su cara y barba, ha de caer consecutivamente en un estado de depresión melancólica cuando se enamora de ese mismo rotoso en otro encuentro inesperado. Luego de su desaparición "-iTodo se lo lleva el viento! ¿En este país todo se lo lleva el viento!-" (147), la Ecuyere entra en un estado depresivo mayor, totalmente incapacitada de trabajar en el circo. El motivo de la foto de Gardel reaparece entonces en la carátula del disco que le regalan el bebé y Tristán para sacarla de su melancolía, y ahora en relación con el verso inicial, "Vieja, fané, descangayada" $(150,156)$, del tango "Esta noche me emborracho", uno de los más cómicamente desgarradores de Discépolo cantados por Gardel ${ }^{18}$. El virtuosismo de Gambaro en su desarrollo del tema de la

\footnotetext{
${ }^{17}$ Según Horacio Ferrer, "La obra de Enrique Santos Discépolo revela en su desencantada concepción de la vida, en su despiadada consignación del fracaso, en sus espectaculares y sobrecogedores contrastes entre el soy, el quisiera o el debiera ser rioplatense, la gravitación indiscutible del grotesco pirandelliano", "El mismo fenómeno que es dable observar en los sainetes de su hermano Armando, 'Mateo', 'Stefano', es fácil contrastarlo con los grandes tangos que Enrique compuso, casi uno por año, desde 1927 hasta 1951, el de su muerte" (Varios , 39, 40). Luis Ordaz aclara: "Todo nos lleva a pensar que Enrique realiza en el tango lo que Armando logra con el 'grotesco criollo': captar y condensar de manera entrañable y por ello tragicómica, el desasosiego y las angustias de una etapa de nuestra realidad político-social que se caracteriza por el fracaso de los empinados sueños del inmigrante (como individualidad y como masa), y su dolorosas consecuencias" (Ordaz, 423).

${ }^{18}$ Octavio Ramírez califica de "tragicomedia" las letras del compositor: "Los de Discépolo no son ni lo uno ni lo otro [trágicos o cómicos] por ser las dos cosas, en dosis perfectamente equilibradas.... Ante la vida que agría, sonríe para no dejarse amargar" (Lara y Poncetti, 292). Esa actitud es tangente a la de la Ecuyere en una de sus "Charlas que no se hicieron": "En el trapecio, pero sobre la tierra, cualquier destino puede pertenecerme, porque tengo derecho a increparlo, menos el de una criatura de amargura. Por eso me digo: todo está bien" $^{\prime \prime}(221)$.
} 
arbitrariedad de la suerte se subraya en este motivo. La letra del tango, aparentemente aplicable en ese momento a la Ecuyere, anegada en su melancolía e incapaz de actuar, funciona mejor como anticipación del destino de María. En su encuentro final con Tristán en el Almacén La María, aparece tan cambiada como la mujer del tango: "Tristán miró sus cabellos oscuros y la caída de los hombros, que era la misma de su recuerdo. Sólo que había más carne y grasa acá .... Tengo que cantar, se dijo Tristán ... pero no pudo, detenido y ahogado por el vientre voluminoso" $(222-23)^{19}$.

Al crear ese tono de tragedia cómica, Gambaro se coloca también dentro de la tradición histórica del teatro argentino en su entronque circense ${ }^{20}$. El circo, los abusos del poder y la monstruosidad del Patrón, proveen un paralelo con la realidad nacional y personal de la autora, claro especialmente en los reclamos "-Aquí no pasó nada-" (203) luego de que se dispone la muerte de la amiga mansa ${ }^{21}$. Mas la escritora se compenetra sobretodo con sus funciones en el desarrollo del teatro, especialmente en el humor físico del mimodrama y la evolución de la sátira social y política libres de censura desde el payaso criollo ${ }^{22}$. Si se ha comparado el teatro de Gambaro con la actuación de Buster Keaton (Carballido, 630), Gambaro parece reafirmarse aquí, en una suerte de "slapstick criollo", modo de presentación no sólo de los episodios en que participa el

\footnotetext{
${ }^{19}$ Incluyo a continuación la letra de "Esta noche meemborracho": Vieja, fané, descangayada, la vi esta madrugada/ salir del cabaret; flaca, dos cuartos de cogote/ y una percha en el escote/ bajo la nuez;/ chueca, vestida de pebeta/ teñida y coqueteando/ su desnudez/ parecía un gallo desplumao/ mostrando, al compadrear/ el cuero picoteao; yo, que sé cuando no aguanto más/ al verla así, rajé/ pa no llorar./ ¡Y pensar que, hace diez años,/ fue mi locura!/ $Q Q u e ́$ llegué hasta la traicion/ por su hermosura!/Eso que hoy es un cascajo/ fue la dulce metedura/ donde yo perdí el honor/que chiflao por su belleza/ le quité el pan a la vieja/me hice ruin y pecador/Que quedé sin un amigo,/ que vivi de mala fe,/que me tuvo de rodillas,/ sin moral, hecho un mendigo,/ cuando se fue/ Nunca soñé que la vería/ en un "requiesca in pace"/ tan cruel como el de hoy./ ¡Mire si no es pa' suicidarse/ que por ese cachivache/ sea lo que soy!/Fiera venganza la del tiempo/que le hace ver deshecho/ lo que uno amó/ Este encuentro me ha hecho tanto mal/ que si lo pienso más/ termino envenenao./Esta noche me emborracho bien,/me mamo ¡bien mamao!/ pa no pensar./(del Valle, 132-34)

${ }^{20}$ Véase especialmente: Castagnino (1969), Castagnino (1981) y Ordaz.

${ }^{21}$ Gambaro apunta: "There are many themes in this novel [Dios no nos quiere contentos]: a feeling of being lost far from my country; the circus is my country to some extent" (Picon Garfield, 69).

${ }^{22}$ El circo criollo "desde muy temprano muestra estrecha interdependencia con el teatro, a punto tal que de él nace toda una modalidad dramática", "prácticamente no tiene jamás problemas de censura eclesiástica y muy pocos de censura política"; sobre Pepino 88 , clown criollo de José Podestá, "su agudeza para captar cuanto flotaba en el aire de la adulta inquietud pública y su capacidad para traducirlo en gracia y sátira .... Pepino 88 fue un payaso que divirtió a los adultos" (Castagnino, 1969, 15, 91).
} 
personaje mudo de Tristán, sino también de los más desgarradores de la novel ${ }^{23}$. La narración evoca ese pasado circense en el anciano del ómnibus del bebé y su nostalgia por el circo Sarrasani (66-68). La Ecuyere (Rosa) coincide nominalmente con una de las mejores ecuestres argentinas, la mejor del mundo en su momento, Rosita de la Plata, mientras que los ancianos trapecistas gemelos, José y Pepé, con José, Pepé Podestá y su payaso Pepino $88^{24}$. Puesto que los personajes de Gambaro aparecen sometidos a los abusos del Patrón, a la vez otro y el mismo en todos los circos de la novela, es dable suponer que la escritora contrasta esas otras épocas de libertad artística teatral o circense con los terrores de la censura que ella misma sufre como esos personajes suyos.

Junto con esas corrientes tragicómicas, Gambaro explora en Dios no nos quiere contentos el complejo y contradictorio optimismo del Voltaire de Candide, optimismo ambivalente y en constante cuestionamiento, pero, a fin de cuentas, reafirmado en el humor frente al sufrimiento, y en la esperanza en la generosidad y el esfuerzo humanos cuando los depuran el dolor y la muerte ${ }^{25}$. Como Gambaro en 1979, Voltaire se encuentra en 1759 en un momento de crisis personal, ahondada ésta ante los desastres de la guerra y de la naturaleza, especialmente el terremoto de Lisboa de 1755 . Si desconfía de la filosofía de Leibnitz, en la

${ }^{23}$ Durante el terremoto que fulmina a los padres de Tristán y algunos vecinos, el niño se encuentra fuera de su casa y por eso se salva del derrumbe. Se observa el humor de Gambaro: "Habían estado comiendo, él afuera, porque no tenía modos en la mesa, le costaba empuñar el cuchillo correctamente, y los trozos caían fuera del plato con tan buena puntería que alcanzaban los ojos ajenos certeramente, y entonces comenzaban las protestas, los coscorrones. Alguien decía, con ojos como ascuas que se apagaban por las lágrimas del escozor del impacto, qué animal trajeron, o sentaron con gente civilizada" (89). Así también, camino al cementerio para los entierros: "Ya partían, cuando vieron a Tristán en la calle. El cortejo se detuvo y todo el mundo comenzó a bajar de los coches, ¿dónde ubicarlo? Una complicación más. Todos opinaban a viva voz . . . finalmente al padre de Maria se le iluminó el semblante con una idea feliz que todos aprobaron, y Tristán acabó a medias extendido en uno de los coches fúnebres, sosteniéndose de la manija del ataúd para no caerse" (16). S6́lo menciono dos de los muchos episodios de la novela.

24 "En 1924 actúa por primera vez en Buenos Aires el Circo Sarrasani, verdadera ciudad ambulante que no pudo entonces llegar totalmente al pueblo por lo costoso de sus espectáculos" (Castagnino, 1969, 148). Sobre Rosalía Robba (1869-1940), Rosita de la Plata, la "ecuyere famosa y disputada", véase Castagnino (1969, 59, 77, 131-33), y Castagnino (1981, 148). Ordaz incluye una foto donde se evidencia la belleza de Rosa (Ordaz 292).

${ }^{25}$ Me resultan útiles el ensayo crítico de Ira Wade y especialmente la "Introducción critica", y el "Análisis de la novela" de la edición de Christopher Thacker. Cito a Thacker para acentuar el paralelo con Gambaro: "le paradoxe d'une œuvre qui contient à elle seule le panorama, le spectacle des événements, des personalités, des désastres, des folies et surtout, des malheurs de l'Europe de cette époque là. Il y a une autre paradoxe. Toujours à travers l'horreur accablante de ces malheurs, il y a le rire libérateur, si direct, si fin, si malicieux, si enragé, si honnête, et d'une force si géniale qu'il est en lui-même une dimension principale du roman" (Thacker 5). 
pregunta reiterativa de Candide, “¿está todo bien?”, o su correlato “¿es éste el mejor de los mundos posibles?", parece abrazar por fin el espíritu de su optimismo al reafirmar el valor de la cooperación y del trabajo: en un mundo inexplicable "nos es preciso cultivar nuestro jardín"26. En el azaroso camino del Candide hacia ese huerto, Voltaire plantea la posibilidad del nuevomundismo como mejormundismo, viendo a América como alternativo espacio de bondad frente a los errores y terrores del otro lado. Mas igual que los sismos no son privativos de Lisboa y alcanzan a Quito, asimismo la pequeñez y el vicio humanos abundan en el Virreinato de Buenos Aires. Es ese derrotero de Candide el local donde sufre la separación y pérdida de la última imagen integral de su amada Cunegonde, de ahí en adelante repetidamente prostituida al punto de quedar irreconocible en su reencuentro final. Negación de mejormundismo, Buenos Aires es el espacio vital que Griselda Gambaro toma para las andariegas aventuras y los insólitos viajes en ómnibus de los personajes de Dios no nos quiere contentos.

He mencionado ya la vena temática del Voltaire de Candide cuando apunté las secciones reflexivas de Gambaro: "Charlas que no se hicieron". Su "Llorá Tristán. Todo está bien"(221) y su reafirmación del valor del trabajo salvador, "Sólo quería sacudirse esa continuidad ininterrumpida de desasosiego y malhumor, de aburrimiento y melancolía. El trabajo le quitaría todo eso" (214), parecen actualizaciones del autor ilustrado. Son especialmente significativos en esa valorización los dos vuelos trascendentales de la Ecuyere en el trapecio, el canto de su amor imposible al rotoso: "Entonces se produjo una situación extraña, la Ecuyere no estaba sola arriba, cerca del techo agujereado de la carpa. Todos los de abajo sintieron que los llevaba con ella, sin miedo saltaban en el aire" (129), y su elegía al bebé muerto: "Esa noche, la Ecuyere creó un número irrepetible ... ella los trasladaba a una región donde no encontraban la irritación de vivir y de morir. Nunca la habian recorrido, no sabían si lo deseaban" (219). Asimismo, cuando sube al techo del prostíbulo con Tristán, "Los chicos miraban a través de los vidrios sucios de la ventana y poco a poco fueron apareciendo por la puerta, con sonrisas casi dolorosas de deseo, tímidos y maravillados" $(254)^{27}$.

La escritora también coincide en situaciones y recursos narrativos con la práctica de Voltaire ${ }^{28}$. La generosidad final de la Ecuyere repite la de Candide, evidente en su repartición del botín de El Dorado, verdadero saco sin fondo. Tanto Candide como Tristán son huérfanos, y como el terremoto de Lisboa para

\footnotetext{
26 Voltaire va del rechazo a la aceptación contradictoria de Leibnitz, cuya filosofía simplificada al extremo lee: “'L'Optimisme' de 1759-1761 dissait quelque chose comme le Meilleur-mondisme: "Tout a été créé par un Dieu bon pour le meilleur des mondes possibles, donc LE TOUT EST BIEN"' (Magnan, 2).

${ }^{27}$ En este sentido véase Starobinski para el ascenso, dentro de la literatura y del arte europeos, del acróbata, el funámbulo o el payaso como figura capaz de alcanzar la experiencia trascendente, el "otro lado".

${ }^{28}$ Sigo principalmente las categorias de Thacker.
} 
Candide, el de Buenos Aires marca un momento crucial en las desgracias de Tristán. La constancia del amor de Candide ante la repetida experiencia de otras formas pervertidas y prostituidas del sexo hacen paralelo con la de Tristán, desde su primer encuentro con el pederastra del ómnibus (26-31), a través de todas sus visitas, reales o soñadas, a la casa de prostitución. Este queda tan perplejo cuando sufre su encuentro con una María mudada, por efecto de la prostitución, como Candide cuando recupera a Cunegonde.

La composición a base de sucesos históricos reales que en la ficción parecen descabellados es otro rasgo que comparten Gambaro y Voltaire. Cabe mencionar los episodios relacionados con desapariciones. En el caso del bebé perdido en el ómnibus, se observan los intentos por devolverlo: "la Ecuyere había corrido a la terminal mientras la madre del bebé, con la imprudencia de la desesperación, había corrido a la comisaría .... - -Se perdió- dijo la Ecuyere. -A mí no me lo cuente-contestó el chofer, harto de que le ofrecieran bebés y no dinero" (72). El mismo episodio muestra otro rasgo en común, la denuncia de las instituciones, según el chofer aconseja, “-Llévelo a la comisaría-remató" (72), y reaccionan los personajes de Gambaro, "-Bueno, bueno- dijo la Ecuyere falsamente entusiasta. - jexcelente idea!-y empujó a Tristán que se había quedado paralizado como si debiera entregar el bebé a los leones. La comisaría, pensó el bebé, a través de los efluvios que le pasaba Tristán, e imágenes de espanto lo asaltaron" (73).

Gambaro utiliza, como Voltaire, la parodia y la sátira bíblica. Recuérdese cómo Tristán contradice el mito que lo nombra. Pueden señalarse en Dios no nos quiere contentos: el bebé como figura de Cristo salvador de Tristán y la Ecuyere; el sueño del diluvio (78-83); la recreación de las pruebas del profeta Daniel en el episodio donde la Ecuyere limpia la jaula del león del circo (115-18); el vuelo de la Ecuyere durante la tormenta, y su descenso como aparición milagrosa sobre el techo del flaco (177); la búsqueda del circo como la de una "tierra prometida" (185) y alusiones directas como la meditación "Las jerarquías de la miseria se suceden al infinito, como las penas de Job" (85).

Gambaro parece replantear con su novela Dios no nos quiere contentos la problemática de Job en su prueba bíblica de paciencia a través de la consideración "La pena no es tan importante", que en distintos momentos de la novela, repiten María (104), el bebé (152) y Tristán (153). Para la Ecuyere, en lo al to del trapecio (o en contacto con su cielo en la tierra), se resuelve en su meditación, "su pena era tan grande que quitaba sentido y volvía inútil su propio tiempo de vivir. $\mathrm{Y}$ sin embargo, era su pena, y no el sentido o sinsentido de vivir, lo que la sostenía bajo las estrellas" (220). Y es el regalo que recibe Tristán con la última mirada del bebé, necesaria para su último encuentro con María: "El dolor nos arma mejor que la felicidad y con esa mirada podría contemplar a esa mujer que tenía enfrente sin deshacerse en el horror" (224). Se cumple así el epígrafe o lema que guía la novela de Gambaro, y que ella toma de Alejandra Pizarnik, "Vida, mi vida, déjate caer, déjate doler, mi vida, déjate enlazar de fuego, de silencio ingenuo, de piedras verdes en la casa de la noche, déjate caer y doler, mi vida", derrotador de la pena desde su mismo apoderarse líricamente del dolor. 


\section{OBRAS CONSULTADAS}

Armando, Rose Marie. Teatroargentino contemporáneo. Buenos Aires: Revista Cultura . Colección Union Carbide, 1985.

Betsko, Kathleen y Rachel Koening. Interviews with Contemporary Women Playwrights. New York: Beech Tree Books, 1987.

Carballido, Emilio. "Griselda Gambaro o modos de hacernos pensar en la manzana". Revista Iberoamericana XXXVI, 73 (octubre-diciembre 1970): 629-34.

Castagnino, Raúl H. Circo, teatro gauchesco y tango. Buenos Aires: Instituto Nacional de Estudios de Teatro, 1981.

El circo criollo. Buenos Aires: Plus Ultra, 1969.

CODEP. Nunca más. Buenos Aires: Editorial Universitaria, 1984.

Lara Tomás de, e Inés Leonilda Roncetti de Panti. El tema del tango en la literatura argentina. Buenos Aires: Ediciones Culturales Argentinas, 1961.

Rougement, Denis de, Love in the Western World, trad. Montgomery Belgion, ed. revisada y aumentada. Princeton: Princeton University Press, 1983.

Valle, Julio del, ed. Antología del tango (Tangos célebres). México: Editores Mexicanos Unidos, 1972.

Gambaro, Griselda. Conversaciones con chicos. Buenos Aires: Siglo Veinte, 2a. ed., 1983.

, Dios no nos quiere contentos. Barcelona: Lumen, 1979.

El desatino. Buenos Aires: Emecé, 1965.

Ganarse la muerte. Buenos Aires: La Flor, 1976.

La cola mágica. Buenos Aires: La Flor, 1975.

Lo impenetrable. Buenos Aires: Torres Agüero, 1984.

Madrigal en ciudad. Buenos Aires: Goyanarte, 1963.

Nada que ver con otra historia. Buenos Aires: Ediciones Noé, 1972.

Una felicidad con menos pena. Buenos Aires: Sudamericana, 1968.

Giella, Miguel Angel, Peter Roster y Leandro Urbina, eds. Griselda Gambaro, Teatro: Nada que ver; Sucede lo que pasa. Ottawa: Girol Books, 1983. [Incluye: "Griselda Gambaroy su obra", y las entrevistas "Griselda Gambaro: laética de la confrontación" (1979) y "Griselda Gambaro: la difícil perfección" (1982)].

Karvelis, Ugné. "L'enfer de Cledy." Le Figaro Littéraire (14-15 diciembre, 1976). Magnan, André ed. Voltaire: Candide ou l'optimisme. Paris: Presses Universitaires de France, 1987.

Méndez-Faith, Teresa. "Sobre el uso y el abuso del poder en la producción dramática de Griselda Gambaro." Revista Iberoamericana, 132-33 (juliodiciembre 1985): 831-41.

Ordaz Luis, ed. Historia del teatro argentino. Buenos Aires: Centro Editor de América Latina, 1982. 
Picon Garfield, Evelyn. Women's Voices from Latin America. Interviews with Six Contemporary Authors. Detroit: Wayne State University Press, 1985. Sábato, Ernesto. Tango. Discusión y clave. Buenos Aires: Losada, 1963.

Simpson, John, y Jana Bennett. The Disappeared. London: Robson Books, 1985.

Spector, Norman, ed. The Romance of Tristan and 1solt. Evanston: Northwestern University Press, 1973.

Starobinski, Jean. Portrait de l'artiste en saltimbanque. Genève: Editions d'Art Albert Skira, 1970.

Taylor, Diana, ed. En busca de una imagen. Ensayos criticos sobre Griselda Gambaro y José Triana. Ottawa: Girol Books, 1989.

Thacker, Christopher, ed. Voltaire, Candide ou l'optimisme. Genève: Droz, 1988.

Varios. El tango (antología). Buenos Aires: Centro Editor de América Latina, 1969.

Wade, Ira O. Voltaire and Candide. A Study in the Fusion of History, Art, and Philosophy. Princeton: Princeton University Press, 1959.

Weston, Jesse L. The Legends of Wagner Drama. Studies in Mythology and Romance. New York: Scribner's Sons, 1900.

Zeydel, Edwin H., ed. The "Tristan and Isolde" of Gottfried von Strassburg. Princeton University Press, 1948. 